\title{
REVIEW
}

\section{Priapism in acute spinal cord injury}

\author{
NV Todd \\ Regional Neurosciences Centre, Royal Victoria Infirmary, Newcastle upon Tyne, UK
}

\begin{abstract}
Study design: Prospective literature review; search via Oldmedline (1958-1965), Medline (1966-2005) and Pubmed.

Objectives: The objective of this study is to review the pathophysiology of priapism in acute traumatic spinal cord injury $(\mathrm{SCl})$; to determine the incidence of priapism in traumatic $\mathrm{SCl}$, whether or not priapism is associated with incomplete or only complete $\mathrm{SCl}$ and whether and what treatment might be required. Methods: This is a review article based upon the available literature in this area.

Results and conclusions: Priapism that follows acute traumatic SCl is high-flow (non-ischaemic) priapism, that is, the blood within the corpus is arterial in nature. Priapism does not occur in all patients with acute $\mathrm{SCl}$. The literature does not allow us to determine in what proportion of patients priapism occurs. Priapism has been reported following a wide variety of spinal cord pathologies including acute $\mathrm{SCl}$, transverse myelitis and postoperative extradural haematoma. In all patients, priapism is associated with complete motor and sensory (American Spinal Injury Association A) paraplegia. Priapism has been reported following spinal shock. Following traumatic $\mathrm{SCl}$, priapism usually settles rapidly without specific treatment being required. Priapism occurs at the moment of complete motor and sensory paraplegia, it does not occur following a delay. There are medicolegal implications: the presence/ absence of priapism assists in determining when the complete spinal cord lesion occurred.
\end{abstract}

Spinal Cord (2011) 49, 1033-1035; doi:10.1038/sc.2011.57; published online 7 June 2011

Keywords: priapism; spinal cord injury; complete cord lesion; incomplete cord lesion.

\section{Introduction}

Priapism is persistent erection of the penis. ${ }^{1}$ In females, persistent erection of the clitoris is known as clitorism. ${ }^{2}$ The frequency and timing of priapism in acute spinal cord injury (SCI) and the level, or levels, most likely to be associated with priapism are debated.

\section{Methods}

A literature search was performed on Oldmedline (19501965), Medline (1966-2005) and Pubmed. The search terms were priapism, penile erection or clitorism plus spinal injury. The search was English language not restricted by time. The primary references were reviewed and supplementary references were taken from the primary source references.

\section{Results}

There is a very restricted literature that has reported priapism in patients with SCI. Gordon et al. ${ }^{3}$ reported six patients with priapism following acute SCI; all six had a complete (American Spinal Injury Association A) spinal cord lesion.

Correspondence: NV Todd, Regional Neurosciences Centre, Royal Victoria Infirmary, Queen Victoria Road, Newcastle upon Tyne, NE1 4LP, UK. E-mail: Jackie@northernmedicalservices.co.uk

Received 2 September 2010; revised 7 April 2011; accepted 17 April 2011; published online 7 June 2011
Rodi et al. ${ }^{4}$ reported a 42-year-old man undergoing posterior spinal fixation for a fracture of L2 associated with ankylosing spondylitis. The patient awoke with priapism and with a complete motor and sensory paraplegia that was a consequence of a large epidural haematoma. The haematoma was decompressed as an emergency, the motor and sensory paraplegia and priapism resolved rapidly. Priapism has been reported following spinal shock, that is, it has been reported in what initially appeared to be a complete spinal cord lesion; the spinal cord lesion resolved. ${ }^{5}$

Other lesions affecting the spinal cord or the cauda equina nerve roots can also cause priapism. Priapism has been reported in patients with spinal stenosis, ${ }^{6}$ sacral tumours, ${ }^{7,8}$ transverse myelitis, ${ }^{9}$ epidural haematoma, ${ }^{4,10}$ transurethral surgery $^{11}$ or spinal anaesthesia. ${ }^{12}$

Following judicial hanging in men, there may be a complete or partial penile erection with or without ejaculation (the terminal, or death, erection). ${ }^{13}$ Priapism has also been associated with fatal gunshot wounds to the brainstem or spinal cord. ${ }^{14}$

\section{Discussion}

Classification of priapism

Priapism has been subdivided into two types: (1) low-flow (ischaemic) or (2) high-flow (non-ischaemic). ${ }^{1}$ Low-flow 
priapism is more common; typically the penile shaft is firm, the glans penis is soft and the priapism is painful. The causes of low-flow priapism include haematological disorders such as leukaemia, ${ }^{15}$ sickle cell anaemia ${ }^{16}$ or diffuse intravascular coagulation, ${ }^{17}$ drugs $^{6}$ or pelvic malignancy. ${ }^{8}$ Blood sampled from the corpus is venous, in appearance and on blood gas analysis. $^{3}$

High-flow priapism is typically caused by injury; injury can be to the perineum ${ }^{1}$ or to the spinal cord. ${ }^{3}$ Other causes of spinal cord dysfunction including spinal stenosis, ${ }^{10}$ sacral tumours, ${ }^{7,8}$ transverse myelitis, ${ }^{9}$ epidural haematoma, ${ }^{4}$ transurethral surgery ${ }^{11}$ or spinal anaesthesia ${ }^{12}$ can, rarely, cause high-flow priapism. In high-flow priapism the penis is usually painless; blood sampled from the corpus is arterial, in appearance and upon blood gas analysis. ${ }^{3}$

\section{Mechanisms}

It is assumed that the mechanism of priapism in most patients with SCI is that abrupt loss of sympathetic input to the pelvic vasculature leads to increased parasympathetic input and uncontrolled arterial inflow directly into the penile sinusoidal spaces. ${ }^{18}$ The majority of spinal cord lesions that are associated with priapism are located in the cervical region, but the lesion can be at any level in the spine. In Gordon et al's ${ }^{3}$ six patients, five had cervical lesions and one had a lesion at T12. In Hammond et al's ${ }^{9}$ three infants with transverse myelitis, all three had cervical cord lesions. The sympathetic outflow arises from the thoracolumbar spine, that is, the spinal cord from approximately $\mathrm{T} 2$ to the conus (L1-2). The sympathetic outflow to the penis and clitoris arises from the lowest levels of the spinal cord, the conus, which is the reason why a lesion at any level in the spinal cord from the brainstem to the conus can be associated with priapism.

Priapism appears invariably to be associated with a complete spinal cord lesion regardless of the aetiology of the complete cord lesion. In Gordon's ${ }^{3}$ six patients with traumatic SCI, and Hammond and Kerr's ${ }^{9}$ three male infants with transverse myelitis, all patients had an (American Spinal Injury Association A) complete motor and sensory paraplegia. If a patient is unconscious because of a traumatic brain injury, priapism is an indication of coexisting SCI. ${ }^{19}$

A SCI that, on clinical examination, is complete can be anatomical, that is, there is physical damage to the motor and sensory pathways in the spinal cord, or it can be physiological (spinal shock). Spinal shock is a physiological cause of traumatic motor and sensory paralysis, which is reversible (typically over several hours or days). Priapism has been reported following spinal shock. ${ }^{5}$ Spinal shock is rare; most patients with traumatic SCI who have complete motor and sensory paraplegia on first assessment have irreversible lesions, which is the reason why the presence of priapism usually carries a poor prognosis for neurological or functional recovery.

Priapism, if it occurs, is normally present at first assessment, ${ }^{3}$ that is, if it occurs it happens rapidly following a complete spinal cord lesion. Where erection occurs following judicial hanging, it occurs at the point of execution, not subsequently. It is reasonable to assume that in SCI patients who have priapism, it occurs at the moment of, or very shortly after, the complete spinal cord lesion.

Not all men with complete SCI develop priapism. It is not known in what proportion of men with a complete spinal cord lesion does priapism occurs.

\section{Evidence from judicial hanging}

Following judicial hanging in men, there may be a complete or partial erection with or without ejaculation (the terminal or death erection). ${ }^{13}$ Judicial hanging was thought to cause death via spinal cord and/or brainstem injury secondary to fracture and/or dislocation of the cervical spine. ${ }^{20-23}$ However, post-mortem examination of 34 cases of execution by judicial hanging (1882-1945) demonstrated an axis ('hangman's') fracture in only 6 cases (18\%) and cervical fracture in only 1 case. ${ }^{24}$ In those persons (the majority) who have no cervical fracture following judicial hanging, it is probable that loss of consciousness and death are the consequences of lacerations to, and haemorrhage from, the carotid or vertebral arteries. ${ }^{25-28}$

\section{Treatment of priapism}

Ischaemic (low-flow) priapism can be a medical emergency. Treatment with alpha-agonists or corporal aspiration of blood is usually required as an emergency to prevent corporal fibrosis and long-term erectile dysfunction. Highflow (non-ischaemic) priapism can usually be managed conservatively. ${ }^{3}$ Rarely, endovascular occlusion of the dilated penile vessels may be required. ${ }^{29}$

Priapism in acute traumatic SCI is a short-lasting phenomenon, which must be distinguished from recurrent or refractory priapism that can occur in patients with chronic SCI. ${ }^{30}$ Once priapism has occurred (following acute traumatic SCI) it usually settles rapidly. In Gordon et al's ${ }^{3}$ six patients with post-SCI priapism, four were treated conservatively and the erection settled spontaneously within $5 \mathrm{~h}$ in all cases. The author has seen one case of persistent priapism $24 \mathrm{~h}$ after complete SCI, which resolved without specific treatment.

\section{Medicolegal implications}

There are implications, medicolegally, in determining the timing and causation of SCI. Injury to the spinal column (fractures and/or dislocations) may be associated with immediate SCI, incomplete or complete. In others there may be injury to the spinal column, which is not associated with any neurological deficit. Patients with potentially unstable injuries to the spinal column must be transferred, transported and examined with in-line spinal immobilisation to prevent excessive movement at the level of an unstable injury. If excess movement at the level of an unstable fracture or dislocation is not prevented, there can be secondary damage to the spinal cord, which could lead to the patient with no initial SCI developing an incomplete or complete SCI that was potentially preventable (or a patient with an incomplete SCI becoming complete). Secondary deterioration of neurological function in patients with SCI is uncommon, occurring in about $4 \%$ of patients. ${ }^{31-33}$ It is probable that in the great majority of patients, secondary 
neurological deterioration is associated with excess movement at the level of an unstable fracture and/or dislocation. ${ }^{34-37}$

Some men with acute SCI never develop priapism. For those that do: if, at the time of first assessment (perhaps by lay people, ambulance paramedics or A\&E staff) priapism is present then we can conclude (in the absence of any further neurological information) that, on a balance of probabilities, the injury to the spinal cord occurred within the past few hours and the spinal cord lesion was complete at the time of those first observations. If, however, on first assessment there was no penile erection and priapism was subsequently identified then, on a balance of probabilities, the complete SCI was not a consequence of the primary injury, but occurred subsequently. As set out above, the overwhelmingly most likely cause of secondary SCI is excessive movement at the level of an unstable fracture and/or dislocation.

\section{Conclusions}

Priapism occurs in a proportion of men with acute traumatic SCI. The proportion of men with acute SCI that develop priapism is not known. Priapism can be associated with injury to any part of the spinal cord from the foramen magnum to the conus. A turgid semi-erect or erect priapism is always associated with a complete (American Spinal Injury Association A) motor and sensory paraplegia. Priapism probably occurs at the moment of, or very shortly after, complete SCI. This is high-flow (arterial) priapism. The priapism settles spontaneously usually within a few hours, occasionally up to $30 \mathrm{~h}$ after the SCI. It, only, rarely requires medical treatment. There are medicolegal implications: if priapism was not present in the pre-hospital or initial hospital phases of management but priapism and complete motor and sensory paraplegia were subsequently identified, the complete SCI may have been a consequence of failure to immobilise the spine during the pre-hospital or early hospital care.

\section{Conflict of interest}

The author declares no conflict of interest.

\section{References}

1 Sadeghi-Nejad H, Seftel AD. The etiology, diagnosis and treatment of priapism: review of the American Foundation for Urologic Disease Consensus Panel Report. Curr Urol Rep 2002; 3: 492-498.

2 Monllor J, Taño F, Arteaga PR, Galbis F. Priapism of the clitoris. Eur Urol 1996; 30: 521-522.

3 Gordon SA, Stage KH, Tansey KE, Lotan Y. Conservative management of priapism in acute spinal cord injury. Urology 2005; 65: 1195-1197.

4 Rodi Z, Strtaus I, Denic K, Deletis V, Vodusek DB. Transient paraplegia revealed by intraoperative neuropsyiological monitoring: was it caused by the epidural anaesthetic or an epidural haematoma? Anesth Analg 2003; 96: 1785-1788.

5 Dawodu ST. Spinal cord injury - definition, epidemiology, pathophysiology. http://emedicine.medscape.com/article/322480overview.

6 Laha RK, Dujovny M, Huang PS. Intermittent erection in spinal canal stenosis. J Urol 1979; 21: 123-124.

7 Greschner M, Krautschick A, Alken P. High-flow priapism leading to the diagnosis of lung cancer. Urol Int 1998; 60: 126-127.
8 Haddad FS. Penile metastases secondary to bladder cancer. Review of the literature. Urol Int 1984; 39: 125-142.

9 Hammond ER, Kerr DA. Priapism in infantile transverse myelitis. Arch Neurol 2009; 66: 894-897.

10 Cuenca PJ, Tulley EB, Devita D, Stone A. Delayed traumatic spinal epidural haematoma with spontaneous resolution of symptoms. J Emerg Med 2004; 27: 37-41.

11 van Arsdalen KN, Chen JW, Smith MJ. Penile erections complicating transurethral surgery. J Urol 1983; 129: 374-376.

12 Thomas A, Woodard C, Rovner ES, Wein AJ. Urologic complications of nonurologic medications. Urol Clin North Am 2003; 30: 123-131.

13 Gallagher JP. A lesson in neurology from the hangman. J S C Med Assoc 1995; 91: 38.

14 Guy WA, Ferrier D. Principles of Forensic Medicine. Ballantyne Press: Edinburgh \& London, 1861; pp, 2: 252-260.

15 Steinhardt GF, Steinhardt E. Priapism in Children with leukemia. Urology 1981; 18: 604-606.

16 Fowler Jr JE, Koshy M, Strub M, Chinn SK. Priapism associated with the sickle cell hemoglobinopathies: prevalence, natural history and sequelae. J Urol 1991; 145: 65-68.

17 Takamura S, Suzuki Y, Hiei T et al. A case of priapism caused by disseminated intravascular coagulopathy [in Japanese]. Hinyokika Kiyo 1987; 33: 453-457.

18 Keoghane SR, Sullivan ME, Miller MA. The aetiology, pathogenesis and management of priapism. BJU Int 2002; 90: 149-154.

19 Sneed RC, Stover SL. Undiagnosed spinal cord injuries in braininjured children. Am J Dis Child 1988; 142: 965-967.

20 Hellier C, Connolly R. Cause of death in judicial hanging: a review and case study. Med Sci Law 2009; 49: 18-26.

21 Wood-Jones F. The ideal lesion produced by judicial hanging. Lancet 1319; 1: 53.

22 Vermooten V. A study of the fracture of the epistropheus due to hanging with a note on the possible causes of death. Anat Rec 1921; 20: 305-311.

23 Shkrum MJ, Green RN, Nowak ES. Upper cervical trauma in motor vehicle collisions. J Forensic Sci 1989; 34: 381-390.

24 James R, Nasmyth-Jones R. The occurrence of cervical fractures in victims of judicial hanging. Forensic Sci Int 1992; 54: 81-91.

25 Spitz WD. Medicolegal Investigations of Death: Guidelines for the Application of Pathology to Crime Investigation. Springfield: Illinois, USA, 1993.

26 Subramanyam BV (ed). Modi's Medical Jurisprudence and Toxicology. Butterworths: New Delhi, India, 1992.

27 Reay DT, Cohen W, Ames S. Injuries produced by judicial hanging. A case report. Am J Forensic Med Pathol 1994; 15: 183-186.

28 Wallace SK, Cohen WA, Stern EJ, Reay DT. Judicial hanging: postmortem radiographic, CT, and MR imaging features with autopsy confirmation. Radiology 1994; 193: 263-267.

29 Numan F, Cakirer S, Işlak C, Oğüt G, Kadioğlu A, Cayan S et al. Posttraumatic high-flow priapism treated by N-butyl-cyanoacrylate embolisation. Cardiovasc Intervent Radiol 1996; 19: 278-280.

30 D'Aleo G, Rifici C, Kofler M, Saltuari L, Bramanti P. Favorable response to intrathecal, but not oral, baclofen of priapism in a patient with spinal cord injury. Spine 2009; 34: E127-E129.

31 Marshall LF, Knowlton S, Garfin SR, Klauber MR, Eisenberg HM, Kopaniky D et al. Deterioration following spinal cord injury. A multicenter study. J Neurosurg 1987; 66: 400-404.

32 Tator CH, Fehlings MG. Review of the secondary injury theory of acute spinal cord trauma with emphasis on vascular mechanisms. J Neurosurg 1991; 75: 15-26.

33 Frankel HI, Hancock DO, Hyslop G, Melzar J, Michaels IS, Ungar $\mathrm{GH}$ et al. The value of postural reduction in the initial management of closed injuries of the spine with paraplegia and tetraplegia. Paraplegia 1969; 7: 179-192.

34 Spinal cord injury. In:Stover E et al. (eds) Clinical outcomes from the model systems $1995 \mathrm{p} 173$.

35 De Le Torre J. Spinal cord injury. Review of basic and applied research. Spine 1981; 6: 315-335.

36 Toscano J. Prevention of neurological deterioration before admission to a spinal cord injury unit. Paraplegia 1988; 26: 143-159.

37 Poonnoose PM, Ravichandran G, McClelland MR. Missed and mismanaged injuries of the spinal cord. Trauma 2002; 53: 314-320. 